\title{
The effect of lactose-isomaltulose-containing growing-up milks on cognitive performance of Indonesian children: a cross-over study
}

\author{
Rini Sekartini ${ }^{1}$, Tjhin Wiguna ${ }^{1}$, Saptawati Bardosono ${ }^{1}$, Dian Novita ${ }^{1}$, Tiana Arsianti $^{1}$, Wim Calame ${ }^{2}$ \\ and Anne Schaafsma ${ }^{3 *}$ \\ ${ }^{1}$ Medical Research Unit, Medical Faculty, University of Indonesia, Jalan Salemba 6, Jakarta 10430, Indonesia \\ ${ }^{2}$ StatistiCal BV, Wassenaar, The Netherlands \\ ${ }^{3}$ FrieslandCampina, Pieter Stuyvesantweg 1,8937 AC Leeuwarden, Amersfoort, The Netherlands
}

(Submitted 17 May 2012 - Final revision received 3 October 2012 - Accepted 3 January 2013 - First published online 17 May 2013 )

\section{Abstract}

Glycaemic response to dietary carbohydrates might have an impact on cognitive performance. The present study investigated the effects of growing-up milks (GUM) with isomaltulose and extra minerals and vitamins or lower protein content on cognitive parameters in children aged 5-6 years. In a blinded, partly randomised, controlled, cross-over study, four GUM were provided, each taken over $14 \mathrm{~d}(2 \times 200 \mathrm{ml} / \mathrm{d})$ : standard (Std) GUM; Std GUM + $5 \mathrm{~g}$ isomaltulose (Iso-5 GUM); Iso-5 GUM with $26 \%$ less protein (Iso-5 LP GUM); Std GUM with 2.5 g isomaltulose and extra Mg, Zn, Se, $\mathrm{D}_{3}, \mathrm{~B}_{1}, \mathrm{~B}_{2}, \mathrm{~B}_{12}$, folic acid and choline (Iso-2.5 GUM). At test days, when GUM replaced breakfast, repeated $(0,60,120$ and 180 min post-dose) cognitive tasks were performed (picture presentation, simple reaction time, digit vigilance, choice reaction time, spatial and numeric working memory and picture recognition). Task performance of all subjects ( $n 50)$ worsened over the morning. Best performance was seen on isomaltulose GUM, most notably at $180 \mathrm{~min}$. Iso-2.5 GUM showed best performance on several parameters of attention and memory, Iso- 5 GUM performed best on parameters of memory and Iso-5 LP GUM was positively associated with parameters of attention but less with memory. Std GUM showed only a benefit on one attention and one memory task. Thus, isomaltulose-enriched GUM positively affected parameters of attention and memory at $180 \mathrm{~min}$ post-dose when compared with Std GUM. Extra minerals and vitamins seem beneficial, whereas lowering protein content might improve attention in particular.

\section{Key words: Isomaltulose: Children: Cognitive performance: Growing-up milks}

Both in adults and children, breakfast consumption improves the ability to concentrate, reaction time, problem solving, learning ability, reasoning, memory and mood, when compared with breakfast omission ${ }^{(1-8)}$.

In evaluating the effects of breakfast on cognitive performance, particularly, dietary carbohydrates are of interest. The effect of dietary carbohydrates on blood glucose depends on the type and amount of ingested carbohydrates. Breakfast containing complex or low-glycaemic index (GI) carbohydrates contributes beneficially to attention and memory skills ${ }^{(2,5,9,10)}$. Micha et al. ${ }^{(11)}$ indicated that the amount of carbohydrates absorbed (GL, glycaemic load) is important, strongly suggesting that slow-release or slowly digested carbohydrates in right amounts could be beneficial to children.

Isomaltulose is a natural derivative of sucrose found in honey and sugar cane and can be produced from sucrose by enzymatic rearrangement of the $\alpha-1,2$ linkage between glucose and fructose. Compared with sucrose, isomaltulose is more stable with respect to $\mathrm{pH}$-dependent hydrolysis and enzymatic splitting in the mouth and intestine ${ }^{(12,13)}$. Isomaltulose is completely digested and absorbed in the small intestine but at a much slower rate than sucrose, resulting in a lower but longer-lasting blood glucose concentration (up to $3 \mathrm{~h}$ post-consumption) and with a concomitant lower insulin response $^{(14,15)}$.

A search on PubMed using the keywords 'isomaltulose and human' revealed forty publications over the last 50 years. Chronologically, the studied subjects moved from digestion, effects on cariogenicity to glycaemic response. Only over the last 8 years, two studies have focused on cognitive performance in adults. In a Japanese study, mental performance decreased more slowly post-dose with isomaltulose than with sucrose when compared with baseline values ${ }^{(16)}$. Among healthy male English adults ${ }^{(14)}$, a lower blood glucose

\footnotetext{
Abbreviations: GI, glycaemic index; GL, glycaemic load; GUM, growing-up milk; Iso-2.5 GUM, standard growing-up milk with 2.5 g isomaltulose per serving and increased levels of some minerals and vitamins; Iso-5 GUM, standard growing-up milk with $5 \mathrm{~g}$ isomaltulose per serving; Iso-5 LP GUM, standard growing-up milk with $5 \mathrm{~g}$ isomaltulose per serving with lowered protein and increased fat and dietary fibre content; Std, standard.
} 
concentration profile was observed following the ingestion of isomaltulose when compared with sucrose milk-based drinks. Both milk drinks did not differ in their effects on cognitive performance up to $115 \mathrm{~min}$ post-dose, suggesting that isomaltulose lacks the beneficial effect on cognitive performance. However, it cannot be excluded that the effect of isomaltulose on cognitive performance occurs at a later time point $(3 \mathrm{~h}$ postconsumption) when derived blood glucose concentrations are expected to be higher when compared with carbohydrates with a higher $\mathrm{GI}^{(15)}$.

Recently, a single-dose study in children with growing-up milks (GUM) having different carbohydrate compositions, including a high lactose-isomaltulose variant, has been published ${ }^{(17)}$. The authors have concluded that subtle changes in GUM formulations, and at relatively low levels of carbohydrates, may have an impact on cognitive performance. The isomaltulose-enriched milk reduced the decline in the power of attention in children aged 5-6 years when compared with a standard milk. Enrichment also limited declines in numeric working memory and picture recognition.

The present study aimed to confirm the positive effects of lactose-isomaltulose-containing GUM, replacing breakfast on test days, on cognitive tasks related to memory and attention in 5-6-year-old Indonesian children. Furthermore, we hypothesised that a combination of extra minerals and vitamins with a lower isomaltulose concentration would have the same cognitive outcome as milks with double the amount of isomaltulose. Finally, since a reduced protein content of the milk might reduce insulin secretion ${ }^{(18)}$, which could result in blood glucose concentrations above baseline for a longer period, an effect on cognitive performance is hypothesised.

\section{Methods}

\section{Subjects}

A total of 100 children from the area Kampung Melayu (East Jakarta, Indonesia) were invited to participate in a screening assessed by the Medical Research Unit (Faculty of Medicine Universitas Indonesia). Based on the inclusion and exclusion criteria, fifty-four apparently healthy children (5-6 years of age, twenty-five boys and twenty-nine girls) were included. The inclusion criteria were: normal to superior score on Wechsler scales; $\mathrm{Hb} \geq 110 \mathrm{mg} / \mathrm{l}$; normal body height and weight according to the WHO standard ${ }^{(19)}$; regular milk consumers. The exclusion criteria for the present study were allergy, chronic infections, thyroid disorders, diabetes, lactose intolerance, and mental disturbances or retarded development. During the study period, children were asked to maintain their standard diet and pattern of activity. Children (and parents) were instructed to consume their dinner before 21.00 hours at the day preceding the test days. The characteristics of the study population are reported in Table 1. All participants received an anti-worm treatment. The present study was conducted according to the guidelines laid down in the Declaration of Helsinki, and all procedures involving the subjects were approved by the Medical Research
Table 1. Baseline characteristics of parents and children included in the study

(Mean values and standard deviations; number of participants and percentages; medians and interquartile ranges (IQR), and ranges)

\begin{tabular}{|c|c|c|c|}
\hline \multirow[b]{2}{*}{ Variables } & \multicolumn{3}{|c|}{ Outcome } \\
\hline & $n$ & & $\%$ \\
\hline \multicolumn{4}{|l|}{ Parents } \\
\hline \multirow{2}{*}{\multicolumn{4}{|c|}{$\begin{array}{l}\text { Education background } \\
\text { Father }\end{array}$}} \\
\hline \multicolumn{2}{|l|}{ Father } & & \\
\hline Less than appropriate* & 7 & & $13 \cdot 0$ \\
\hline Appropriate and higher & 47 & & $87 \cdot 0$ \\
\hline \multicolumn{4}{|l|}{ Mother } \\
\hline Less than appropriate* & 6 & & $11 \cdot 2$ \\
\hline Appropriate and higher & 48 & & 88.8 \\
\hline \multicolumn{4}{|l|}{ Working status } \\
\hline \multicolumn{4}{|l|}{ Father } \\
\hline Permanent income & 26 & & 48.2 \\
\hline Non-permanent income & 28 & & $51 \cdot 8$ \\
\hline \multicolumn{4}{|l|}{ Mother } \\
\hline Permanent income & 5 & & $9 \cdot 3$ \\
\hline Non-permanent income & 49 & & $91 \cdot 7$ \\
\hline \multicolumn{4}{|l|}{ Children } \\
\hline \multicolumn{4}{|l|}{ Age (months) } \\
\hline Mean & & 72.54 & \\
\hline SD & & 6.57 & \\
\hline \multicolumn{4}{|l|}{ Sex } \\
\hline Boys & 25 & & $46 \cdot 3$ \\
\hline Girls & 29 & & 53.7 \\
\hline \multicolumn{4}{|l|}{ Weight $(\mathrm{kg})$} \\
\hline Median & & 17.65 & \\
\hline IQR & & $6 \cdot 71$ & \\
\hline Range & & $12.94-33.94$ & \\
\hline \multicolumn{4}{|l|}{ Height $(\mathrm{cm})$} \\
\hline Mean & & $112 \cdot 06$ & \\
\hline SD & & 6.95 & \\
\hline \multicolumn{4}{|l|}{ Weight-for-age Z-score } \\
\hline Median & & -1.26 & \\
\hline IQR & & $2 \cdot 23$ & \\
\hline Range & & -3.30 to 5.04 & \\
\hline \multicolumn{4}{|l|}{ Height-for-age Z-score } \\
\hline Median & & -1.04 & \\
\hline IQR & & 1.75 & \\
\hline Range & & -4.01 to 4.43 & \\
\hline Weight-for-height $Z$-score & & & \\
\hline Median & & -0.62 & \\
\hline IQR & & 1.99 & \\
\hline Range & & -2.05 to 3.98 & \\
\hline Underweight status $†$ & 8 & & $14 \cdot 8$ \\
\hline Stunted status $\dagger$ & 9 & & $16 \cdot 7$ \\
\hline Wasted status $\dagger$ & 1 & & 1.9 \\
\hline $\mathrm{Hb}$ value $(\mathrm{mg} / \mathrm{l})$ & & & \\
\hline Mean & & $120 \cdot 5$ & \\
\hline SD & & $8 \cdot 3$ & \\
\hline Anaemic status & 2 & & 3.7 \\
\hline Daily energy intake (kJ) & & & \\
\hline Mean & & 5298.09 & \\
\hline SD & & 934.72 & \\
\hline Daily protein intake (g) & & & \\
\hline Mean & & $40 \cdot 81$ & \\
\hline SD & & 14.69 & \\
\hline Daily carbohydrate intake (g) & & & \\
\hline Mean & & $153 \cdot 80$ & \\
\hline SD & & 34.96 & \\
\hline Daily Fe intake (mg) & & & \\
\hline Median & & $4 \cdot 2$ & \\
\hline IQR & & $2 \cdot 5$ & \\
\hline Range & & $1.9-9.8$ & \\
\hline
\end{tabular}

* Less than appropriate $=$ less than 9 years of formal education. $\dagger$ Less than -2 sD. 
Ethics Committee of Medical Faculty Universitas Indonesia. Written informed consent was obtained from the parents of the subjects. On each test day, children received small toys or stationery items, as an incentive for completing the cognitive performance tasks. The present trial has been registered as NTR2313 (Netherlands Trial Registry).

\section{Study design}

The present study concerns a blinded, partly randomised, reference product-controlled, cross-over study. Each child received four different milk products: standard (Std) GUM; Std GUM with $5 \mathrm{~g}$ isomaltulose per serving (Iso-5 GUM); Iso-5 GUM with lowered protein content (Iso-5 LP GUM); Std GUM with $2.5 \mathrm{~g}$ isomaltulose in combination with additional minerals and vitamins (Iso-2.5 GUM). Energy contributions of Std GUM, Iso-5 GUM and Iso-2.5 GUM were the same, and only slightly higher for Iso-5 LP GUM (335 v. $322 \mathrm{~kJ} / 100 \mathrm{ml}$ ). More detailed information of the products can be found in Table 2 . The test products were each provided during $14 \mathrm{~d}$, two servings per $\mathrm{d}(2 \times 200 \mathrm{ml})$, and no washout period between the different products. Washout was not necessary because the three randomised products (Std GUM, Iso-5 GUM and Iso-5 LP GUM) were considered to have acute effects, whereas the non-randomised final product containing the extra vitamins and minerals also might have time-dependent effects (improving vitamin/ mineral status). The order of the three randomised treatments was based on a $3 \times 3$ Latin square design (Table 3 ), using the date of entry and the sequence order of consumption as determining factors.

A week before the study, parents were given printed information on study requirements for the children. On the day before each test day, parents were again reminded to have their children arrived at the research centre before 08.00 hours, to maintain a standard pattern of activity, to consume dinner before 21.00 hours and to refrain from eating or drinking except plain water from 21.00 hours onwards until arrival at the research centre the next day. Parents were asked about their children's adherence to the study requirements upon arrival at the institute.

Major aspects of attention, working and episodic memory were studied using a computerised cognitive performance test battery (United BioSource Corporation) comprising the tests in the order presented below.

Picture presentation. A series of twenty pictures of everyday scenes, animals and objects were presented to the children to remember.

Simple reaction time. Children were instructed to press the 'YES' response button as quickly as possible every time the word 'YES' was presented on the screen. A total of fifty stimuli were presented with a varying inter-stimulus interval between 1 and $3.5 \mathrm{~s}$. The task lasted approximately $2 \mathrm{~min}$ The average reaction time is the outcome measure of this task.

Table 2. Composition of the test products* per $100 \mathrm{ml}$

\begin{tabular}{|c|c|c|c|c|}
\hline & Std GUM & Iso-5 GUM & Iso-5 LP GUM & Iso-2.5 GUM \\
\hline Energy (kJ) & 322 & 322 & 335 & 322 \\
\hline Protein $(\mathrm{g})$ & $2 \cdot 7$ & $2 \cdot 7$ & $2 \cdot 0$ & $2 \cdot 7$ \\
\hline Fat $(\mathrm{g})$ & $2 \cdot 4$ & $2 \cdot 4$ & 3.0 & $2 \cdot 4$ \\
\hline Carbohydrates (g) & $11 \cdot 3$ & $11 \cdot 3$ & $11 \cdot 3$ & $11 \cdot 3$ \\
\hline Lactose $(\mathrm{g})$ & $5 \cdot 0$ & $5 \cdot 0$ & $5 \cdot 0$ & $5 \cdot 0$ \\
\hline Maltodextrin (g) & 4.3 & 2.5 & 2.5 & 3.0 \\
\hline Sucrose (g) & 1.9 & 1.3 & 1.3 & 1.9 \\
\hline Isomaltulose (g) & & $2 \cdot 5$ & 2.5 & 1.3 \\
\hline Dietary fibre $(\mathrm{g})$ & 0.8 & 0.8 & $1 \cdot 0$ & $0 \cdot 8$ \\
\hline \multicolumn{5}{|l|}{ Minerals } \\
\hline $\mathrm{Mg}(\mathrm{mg})$ & & $8 \cdot 2$ & & 24.5 \\
\hline $\mathrm{Zn}(\mathrm{mg})$ & & 0.5 & & 0.9 \\
\hline I $(\mu \mathrm{g})$ & & $20 \cdot 0$ & & $20 \cdot 0$ \\
\hline Se $(\mu \mathrm{g})$ & & 1.8 & & 3.7 \\
\hline \multicolumn{5}{|l|}{ Vitamins } \\
\hline$D_{3}(\mu \mathrm{g})$ & & $1 \cdot 0$ & & $1 \cdot 3$ \\
\hline$B_{1}(\mu \mathrm{g})$ & & $82 \cdot 0$ & & $150 \cdot 0$ \\
\hline$B_{2}(\mu \mathrm{g})$ & & $105 \cdot 0$ & & $150 \cdot 0$ \\
\hline Folic acid $(\mu \mathrm{g})$ & & $12 \cdot 0$ & & $25 \cdot 0$ \\
\hline$B_{12}(\mu \mathrm{g})$ & & 0.25 & & 0.32 \\
\hline Choline (mg) & & 24.0 & & 32.0 \\
\hline Calculated Gl† & $70 \cdot 0$ & $59 \cdot 2$ & 59.2 & 62.9 \\
\hline GL $\neq$ (200 ml per serving) & $15 \cdot 8$ & 13.4 & 13.4 & $14 \cdot 2$ \\
\hline
\end{tabular}

Std GUM, standard growing-up milk; Iso-5 GUM, Std GUM with $5 \mathrm{~g}$ isomaltulose per serving; Iso-5 LP GUM, Std GUM with $5 \mathrm{~g}$ isomaltulose per serving with lowered protein and increased fat and dietary fibre content; Iso-2.5 GUM, Std GUM with $2.5 \mathrm{~g}$ isomaltulose per serving and increased levels of some minerals and vitamins; Gl, glycaemic index; GL, glycaemic load.

* Test products are prepared by mixing one sachet $(45.4 \mathrm{~g}$ powder) with $180 \mathrm{ml}$ of warm water.

† Sum of the products of individual carbohydrates and their Gl divided by the total amount of carbohydrates, using the following GI: lactose 46; sucrose 68 ; maltodextrin 100 , isomaltulose 40 .

$\mp \mathrm{GL}$ is the sum of the products of individual carbohydrates per serving $(200 \mathrm{ml})$ and their $\mathrm{Gl}$, divided by 100 $\mathrm{A} \mathrm{GL}>20$ is high, $11-19$ is medium and 10 or less is considered to be low ${ }^{(28)}$. 
Table 3. Treatment schedule

\begin{tabular}{lcccc}
\hline & $0-14 d$ & $15-29 d$ & $30-44 d$ & $45-59 d$ \\
\hline Sequence 1 & A & B & C & D \\
Sequence 2 & C & B & A & D \\
Sequence 3 & B & A & C & D \\
\hline
\end{tabular}

A, standard growing-up milk (Std GUM); B, Std GUM with $5 \mathrm{~g}$ isomaltulose per serving; C, Std GUM with $5 \mathrm{~g}$ isomaltulose per serving with lowered protein $(-0.7 \mathrm{~g})$ and increased fat $(0.48 \mathrm{~g})$ and dietary fibre $(0.22 \mathrm{~g})$ content; D, Std GUM with $2.5 \mathrm{~g}$ isomaltulose per serving and increased levels of some minerals and vitamins.

Digit vigilance. A target digit was displayed on the screen that was then followed by the display of a series of 450 digits at the rate of $150 / \mathrm{min}$. Children were instructed to respond as quickly as possible every time a digit in the series matched the target digit. The task lasted for 3 min. The outcome measures of this task are the percentage of correctly detected targets, the average reaction time for correct detections and the number of false alarms

Choice reaction time. Children were instructed to respond to the words 'YES' and 'NO' as they appeared on the screen by pressing the corresponding button as quickly as possible. A total of fifty trials were presented during which each stimulus word was chosen randomly with equal probability and at a varying inter-stimulus interval between 1 and $3.5 \mathrm{~s}$. The task lasted approximately $2 \mathrm{~min}$. The choice reaction time is measured as the percentage of correct responses and the average reaction time of correct responses.

Spatial working memory. A picture of a house was shown on the screen for $10 \mathrm{~s}$ with four of the nine windows lit. Children were instructed to memorise the position of the lit windows, and were then presented with thirty-six subsequent presentations of the house, each time with a single window lit. The children were required to decide whether or not the single window that was lit had been lit in the original presentation, and to press the 'YES' or 'NO' button as quickly as possible. The task lasted approximately $2 \mathrm{~min}$. The sensitivity index and the average speed of correct responses are outcome measures of spatial working memory.

Numeric working memory. A series of five digits were presented, one every $1.15 \mathrm{~s}$ for the children to remember. Immediately after this, a series of thirty probe digits were presented one at a time, and the children had to decide whether or not each digit was the one they had been asked to remember, and to press the 'YES' or 'NO' button as quickly as possible. The task lasted for approximately $2 \mathrm{~min}$. This task is represented by the sensitivity index and the average speed of correct responses.

Picture recognition. The original pictures presented previously, plus twenty similar but different pictures were presented one at a time in a randomised order. For each picture, children were required to indicate whether the picture was one of those originally presented by pressing the 'YES' or 'NO' button as quickly as possible. The task lasted approximately $1.5 \mathrm{~min}$. The outcome measures of picture recognition are the sensitivity index and the average speed of correct responses.

Composite scores. Principal components analysis has shown that the various measures from the three attention tasks load on two different factors, whereas the speed measure from three different memory tasks loads on one factor, and composite scores can be created based on these loadings. These factors are described below.

Power of attention. The speed measures from the three attention tasks (simple and choice reaction time, and digit vigilance) reflect the intensity of concentration at a particular moment.

Continuity of attention. The accuracy measures from the choice reaction time and the digit vigilance task reflect the ability to sustain attention and avoid error.

Speed of memory. The sum of the speed measures from the spatial and numeric working memory tasks and the picture recognition tasks.

United BioSource Corporation was involved in the training programmes for the researchers and data evaluation. All children completed four training sessions shortly before the first test day in order to ensure an optimal level of performance for the baseline assessment. On each test day, cognitive performance tests (pre-dose (baseline), and at 60, 120 and $180 \mathrm{~min}$ post-dose) were conducted at the start of the study (as an acute effect), and at the end of the first, second, third and fourth intervention periods (as a sustained effect). Test drinks at the test days were provided in calibrated cups and were consumed within $15 \mathrm{~min}$. After that, they were restricted from eating for the next $3 \mathrm{~h}$. Any leftover of the test drinks was recorded. Children were tested simultaneously in a classroom, with the children seated at tables in one row, behind each other. In between the tests, children could play in the test room. After completion of the 180 min measurement, children were served with food and beverages.

\section{Data analysis}

The number of approximately fifty participants, including a potential dropout rate of $5 \%$, was based on the outcome in the study of Taib et $a l .{ }^{(17)}$. In their study, thirty children participated and although significant effects were found on cognitive parameters, we increased the total number of children to compensate for a potentially smaller difference in the findings between the various groups.

A quality data review was conducted on the blinded data before receipt of the randomisation code. Based on this review, all data (except for those who did not consume $75 \%$ of the test product) were approved.

Statistical analysis was performed based on the change in response per person. By doing this, inter-variation is minimised (high $v$. low responders).

For each parameter, the values per person per time interval were subtracted from those at the start of the experiment. This resulted in changes per time interval, which were tested using multiple stepwise regression analysis with a dummy variable ${ }^{(20)}$. The regression equation applied was as follows:

$$
y=\left(a_{1} x_{1}\right)+\left(a_{2} x_{2}\right)+\left(a_{3} x_{3}\right)+a_{4},
$$

where $y$ is the change in outcome per person per time interval; $x_{1}$ is the dummy variable, taking the values 0 for product 
I and 1 for product II; $x_{2}$ is the time interval; $x_{3}=\left(x_{1}\right) \times\left(x_{2}\right)$; $a_{1-4}$ are coefficients.

By filling in the formula, a statistical comparison between two plots can be established:

(1) one assigned with ' 0 ' as the dummy variable, which results in the following equation:

$$
y=\left(a_{2} x_{2}\right)+a_{4}
$$

(2) one assigned with ' 1 ' as the dummy variable, which results in the following equation:

$$
y=\left(a_{2}+a_{3}\right) x_{2}+\left(a_{1}+a_{4}\right) .
$$

In these equations, $a_{3}$ describes the difference in slope between the two plots (time effect of the product during the intervention), while $a_{1}$ characterises the difference in overall intensity (constant effect, already starting at the first time interval) throughout the whole interval of the study. These coefficients can be tested via the $t$ test within the regression analysis itself ${ }^{(20)}$. Fitting of the equation was done by ANOVA and $F$-test. In addition to a linear relationship, a quadratic (parabolic) relationship was investigated as well. This did not result in a substantially different outcome.

Since the present study follows a repeated measurement design, a potential subject effect on the outcome was checked via ANCOVA and found to be absent. Using the same approach, it was observed that order of consumption did not affect the outcome in the present study either.

Analyses were done using STATA, version 10 (StataCorp). Throughout the study, using two-sided testing, $P$ values of 0.05 or lower were considered to be statistically significant.

\section{Results}

During the study, four children dropped out because of being incapable to do the cognitive performance tasks ${ }^{(n 2)}$, refusal of parents to continue with the study ${ }^{(n 1)}$ or continuous consumption of less than $75 \%$ of the test product ${ }^{(n 1)}$. From the fifty remaining children, some did not consume a minimum of $75 \%$ of the test product at a particular test day and were therefore excluded from the final evaluations for that particular day. For day 0 , this was the case for five subjects $(2 \times \mathrm{Std}$ GUM, $2 \times$ Iso-5 LP GUM and $1 \times$ Iso-5 GUM) and for day 14 for one subject $(1 \times$ Iso- 5 LP GUM).

For the studied parameters, most treatments showed decrements in performance compared with baseline. Only speed of memory showed improvements when compared with baseline. The results for each cognitive parameter (next sections) and the differences between the parameters are based on outcomes as measured on the last days of each 14 d intervention period. An overview of the several cognitive effects and the differences between the four test products is provided in Table 4 .

\section{Power of attention}

Based on the change in this parameter, Iso-5 LP GUM provided the best results (lowest increase) when compared with Iso-5 GUM ( $P=0 \cdot 048$; Fig. 1 ). Both products were isomaltulose enriched, but Iso-5 LP GUM had a lower protein content.

\section{Continuity of attention}

With regard to the change in this parameter, Iso-2.5 GUM is superior to Iso-5 GUM ( $P=0 \cdot 019$; Fig. 2). Furthermore, there is an effect of time when comparing Iso-5 GUM with Iso-5 LP GUM $(P=0.041)$ and Iso-2.5 GUM $(P=0.031)$.

Table 4. Overview of significant effects or trend effects between the products standard growing-up milk (Std GUM) (A), Std GUM with $5 \mathrm{~g}$ isomaltulose per serving (B), Std GUM with $5 \mathrm{~g}$ isomaltulose per serving with lowered protein and increased fat and dietary fibre content (C) and Std GUM with $2.5 \mathrm{~g}$ isomaltulose per serving and increased levels of some minerals and vitamins (D) with

\begin{tabular}{|c|c|c|c|c|c|c|}
\hline Domain & Task & Outcome measure & A & B & $\mathrm{C}$ & $\mathrm{D}$ \\
\hline \multirow[t]{5}{*}{ Attention } & Power of attention & Composite score & & & $>\mathrm{B}^{*}$ & \\
\hline & Continuity of attention & Composite score & & & & $>\mathrm{B}+$ \\
\hline & Digit vigilance & Speed & $>D^{*}$ & & $\begin{array}{l}>\mathrm{A} \dagger \\
>\mathrm{B} \dagger \\
>\mathrm{D}\end{array}$ & \\
\hline & Choice reaction time & Speed & & & & $>$ A $\dagger$ \\
\hline & & & & & & $\begin{array}{l}>\mathrm{B \dagger} \\
>\mathrm{CH}\end{array}$ \\
\hline \multirow[t]{7}{*}{ Working memory } & Spatial working memory & Speed & & & & $>\mathrm{C}+$ \\
\hline & Numeric working memory & $\begin{array}{l}\text { Sensitivity index } \\
\text { Speed }\end{array}$ & $>\mathrm{B} \dagger$ & $>C^{*}$ & $>\mathrm{B}^{*}$ & $>\mathrm{B} \dagger$ \\
\hline & Picture recognition & Composite score & & $>C^{*}$ & & \\
\hline & Picture recognition & New stimuli accuracy & & $>A \dagger$ & & \\
\hline & & & & $>\mathrm{C} \dagger$ & & \\
\hline & & Sensitivity index & & $>\mathrm{C} \dagger$ & & \\
\hline & & Speed & & $>A^{*}$ & & $>\mathrm{A} \dagger$ \\
\hline Speed of memory & Speed of memory & Composite score & & $>\mathrm{C} \dagger$ & & $>\mathrm{C} \dagger$ \\
\hline
\end{tabular}
regard to the several cognitive performance tasks $\ddagger$

${ }^{\star} P<0.05$.

$\dagger P<0.02$.

$¥$ Composition of products A-D can be found in Table 2. Data are expressed as product in column heading being better than ( $>$ ) product indicated for the several tasks. 


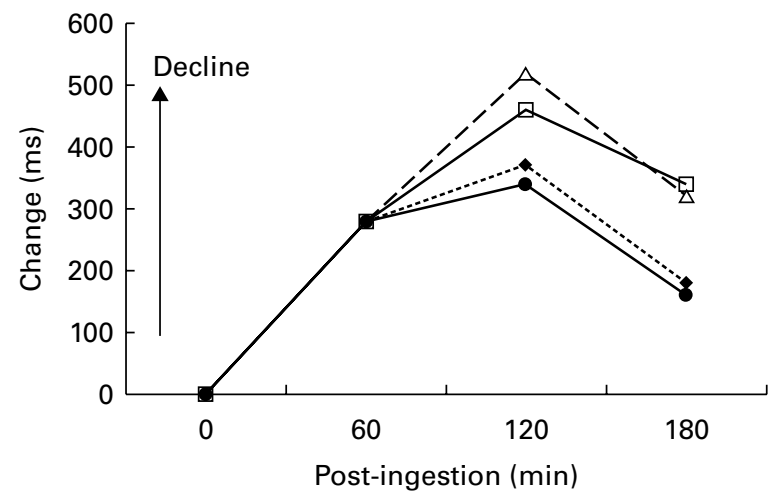

Fig. 1. Effect of the milk products on the change in power of attention standard growing-up milk (Std GUM; 口); Std GUM with $5 \mathrm{~g}$ isomaltulose per serving (Iso-5 GUM; $\Delta$ ); Std GUM with $5 \mathrm{~g}$ isomaltulose per serving with lowered protein and increased fat and dietary fibre content (Iso-5 LP GUM; •); Std GUM with $2.5 \mathrm{~g}$ isomaltulose per serving and increased levels of some minerals and vitamins ( $\bullet$ ). Data are mean values. Iso-5 LP GUM was significantly different from Iso-5 GUM $(P<0.05)$. For the composition of each milk product, refer to Table 2 .

\section{Digit vigilance speed}

The results of the stepwise regression using the change in outcome revealed that there was a significant difference in the effect on time. Std GUM performed worse than Iso-5 LP GUM $(P<0.02)$, whereas Std GUM performed better than Iso- 2.5 GUM $(P<0 \cdot 05)$. The same was observed between Iso-5 LP GUM and Iso-5 GUM $(P<0.006)$, and Iso-5 LP GUM and Iso-2.5 GUM $(P<0.003$; Fig. 3$)$. Obviously, the product Iso-5 LP GUM established a better response in digit vigilance speed (in ms) when compared with the other products at $180 \mathrm{~min}$.

\section{Choice reaction time}

This task had two outcome measures, speed and accuracy. For speed, the results of the analysis showed that during the time interval of the intervention, Iso-2.5 GUM performed better when compared with Std GUM $(P<0 \cdot 01)$, Iso-5 GUM $(P<0.01)$ and Iso-5 LP GUM $(P<0.02)$ (Fig. 4). The improved response is shown at 120 and $180 \mathrm{~min}$ post-dose, and after an initial decrease at $60 \mathrm{~min}$. No differences were found between the products with regard to the outcome measure accuracy.

\section{Quality of working memory}

No differences were found between the four products, although subjects who consumed Iso-2.5 GUM showed a trend in having the slowest rate of decline for this task, especially during the first $2 \mathrm{~h}$ post-dose.

\section{Spatial working memory}

This task had two outcome measures, the sensitivity index and the speed of correct responses. Performance in the sensitivity index declined significantly over the morning under all conditions, without differences between the various treatments.

For the speed of correct responses, Iso-5 LP GUM showed a significant decrease in speed (bigger change) when compared with the product Iso-2.5 GUM $(P<0 \cdot 01)$.

\section{Numeric working memory}

The sensitivity index worsened in all conditions compared with baseline. Comparisons between the conditions revealed that Iso-5 GUM performed significantly worse than Std GUM $(P=0.015), \quad$ Iso-5 LP GUM $(P=0.032)$ or Iso- 2.5 GUM ( $P=0 \cdot 001$ ). For speed, performance on Iso-5 LP GUM declined when compared with pre-dose, which resulted in a worse performance when compared with Iso-5 GUM $(P<0.04)$, at 180 min post-dose.

\section{Picture recognition}

This task had four outcome measures: sensitivity index; speed; original stimuli accuracy; new stimuli accuracy. Based on the change in the outcome measure 'new stimuli accuracy (\%)', Std GUM showed a bigger decrease in performance during the test period than Iso-5 GUM $(P=0.005)$, but was not different from Iso- 2.5 GUM $(P=0.087)$. From $60 \mathrm{~min}$ post-dose onwards, the plot of Iso-5 GUM was constantly at a higher level than Iso-5 LP GUM $(P=0.018)$, and this was also the case for the sensitivity index. For speed, Std GUM performed slower than Iso-5 GUM $(P=0.021)$ and Iso-2.5 GUM ( $P=0.017)$. No differences were found between the groups with regard to the original stimuli accuracy.

\section{Speed of memory}

All the products showed an improvement in speed of memory between 120 and $180 \mathrm{~min}$ post-dose, but for the product Iso-2.5 GUM, this improvement already started at $60 \mathrm{~min}$ post-dose (Fig. 5).

From 60 min onwards during the test period, the plot Iso- 5 GUM was parallel to the plot Iso-5 LP GUM but at a constantly higher level $(P=0 \cdot 019)$, which means the speed of memory on Iso-5 GUM was quicker than that on Iso-5 LP GUM. The plots Iso-5 LP GUM and Iso-2.5 GUM started at the same level at $60 \mathrm{~min}$ post-dose. However, Iso-2.5 GUM showed a

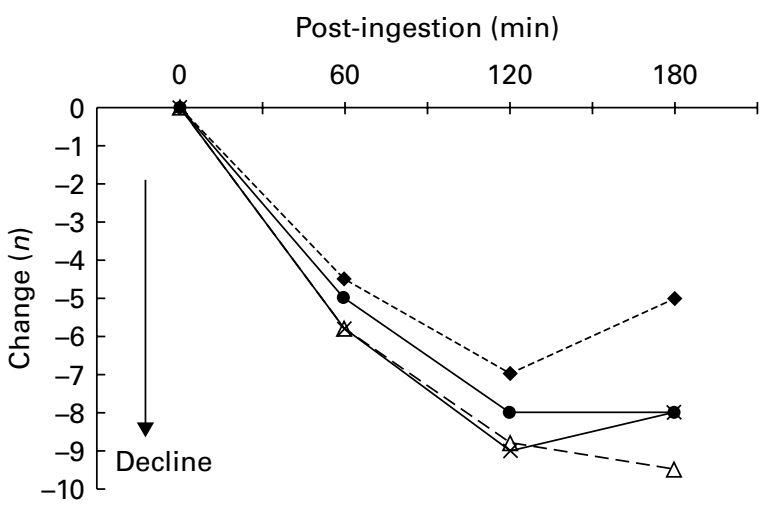

Fig. 2. Effect of the milk products on the change in continuity of attention: standard growing-up milk (Std GUM; $\square$ ); Std GUM with $5 \mathrm{~g}$ isomaltulose per serving (Iso-5 GUM; $\Delta$ ); Std GUM with $5 \mathrm{~g}$ isomaltulose per serving with lowered protein and increased fat and dietary fibre content $(\bullet)$; Std GUM with $2.5 \mathrm{~g}$ isomaltulose per serving and increased levels of some minerals and vitamins (Iso-2.5 GUM; $\bullet$ ). Data are mean values. Iso-2.5 GUM was significantly different from Iso-5 GUM $(P<0.02)$. For the composition of each milk product, refer to Table 2. 


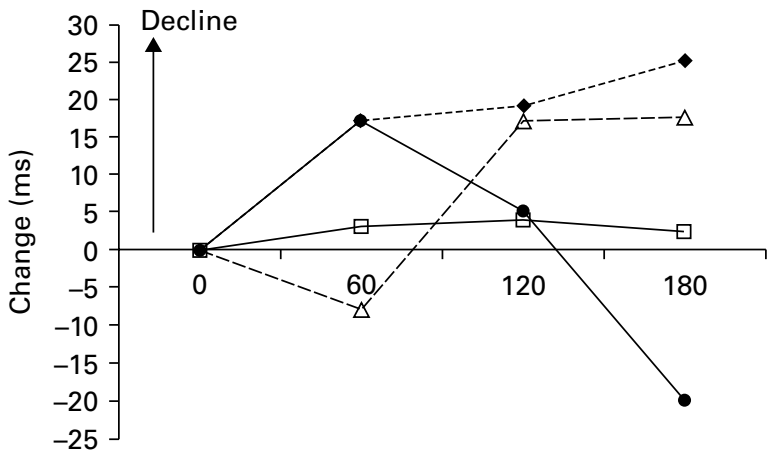

Post-ingestion ( $\mathrm{min}$ )

Fig. 3. Effect of the milk products on the change in digit vigilance speed: standard growing-up milk (Std GUM; $\square$ ); Std GUM with $5 \mathrm{~g}$ isomaltulose per serving (Iso-5 GUM; $\triangle$ ); Std GUM with $5 \mathrm{~g}$ isomaltulose per serving with lowered protein and increased fat and dietary fibre content (Iso-5 LP GUM; •); Std GUM with $2.5 \mathrm{~g}$ isomaltulose per serving and increased levels of some minerals and vitamins (Iso-2.5 GUM; $\bullet$ ). Data are mean values. Std GUM was significantly different from Iso-2.5 GUM $(P<0.05)$. Iso-5 LP GUM was significantly different from Std GUM $(P<0.02)$, Iso-5 GUM $(P<0.006)$ and Iso-2.5 GUM $(P<0.003)$. For the composition of each milk product, refer to Table 2.

significantly better improvement within the interval of the present study than Iso-5 LP GUM $(P=0 \cdot 003)$.

\section{Discussion}

Similar to previous findings in children ${ }^{(4,5,9,17)}$, the present study identified declines in attention and aspects of working and episodic memory over the morning. However, as hypothesised and shown before ${ }^{(17)}$, the present study also indicates that GUM with a carbohydrate composition including isomaltulose shows beneficial effects (decreased declines) on parameters of attention and memory, most notably at $180 \mathrm{~min}$ after consumption. More specifically, the product with only half the amount of isomaltulose $(2.5 \mathrm{~g} /$ serving: Iso-2.5 GUM) but additionally enriched with some minerals and vitamins showed the best overall results being significantly different from the reference product (choice reaction time and picture recognition speed), the product Iso-5 GUM (continuity of attention, choice reaction time and numeric working memory) and the product Iso-5 LP GUM (choice reaction time, spatial working memory and speed of memory). It seems that Iso-5 LP GUM and Iso-2.5 GUM optimise attention parameters, whereas Iso-5 GUM performs well with respect to working memory. The reference product Std GUM was, except for two occasions, never the most positively outspoken product.

It is indicated that both the GI of breakfast and the GL (product of the amount of available carbohydrate per serving and GI) are important for cognitive performance in humans ${ }^{(11)}$. Dependent on the combination of GL and GI, the magnitude of elevation in blood glucose and associated insulin response is affected. The higher the insulin response, the faster the decline in blood glucose concentrations. Furthermore, there is evidence that decreasing blood glucose concentrations (resulting in mild hypoglycaemia) stimulate transient cortisol secretion $^{(21)}$. Also in this case, the cortisol response will be stronger in case the decline in blood glucose concentration is faster. One of the primary functions of cortisol is to increase blood glucose through gluconeogenesis. It has been shown that cortisol secretory pulses stimulate alertness in young adults $^{(22,23)}$. Besides, there is accumulating evidence for a direct impact of blood glucose and associated insulin concentrations on brain fuelling. Receptors for insulin and transporters for glucose are widespread in brain tissue with differences in densities between several brain regions. Associations between insulin and cognitive outcomes such as learning and memory have been established ${ }^{(24,25)}$. Finally, in a mixture of low- and medium-high-GI carbohydrates, low-GI carbohydrates such as isomaltulose still supply glucose for absorption up to $3 \mathrm{~h}$ post-consumption ${ }^{(15)}$.

In the study of Micha et al. ${ }^{(11)}$ in children aged $11-14$ years old, the combination of calculated low GI (forty-eight) and high GL (forty-one per serving) improved learning through beneficial effects on alertness, attention, improved declarative verbal memory and improved vigilance. Furthermore, kids on low-GI products were happy, less nervous and more confident. In high-GI groups (strong insulin response), for low as well as high GL, increased cortisol levels were detected. In the present study, the GL per serving was much lower than the lowest GL in the study of Micha et al. ${ }^{(11)}$. Small differences exist between the lowest $(59 \cdot 2 v$. 48) and highest GI (70v. 61) of both studies. The GI/GL combination of Iso- 2.5 GUM (62.9/14.2) was closest to the high GI/low GL (61/28) of Micha et al. ${ }^{(11)}$. They showed positive effects on vigilance (attention), Stroop task (reaction time), speed information processing and short-term memory. As mentioned previously, these children also showed higher cortisol concentrations. In the present study, Iso-2.5 GUM showed beneficial effects on continuity of attention, choice reaction time, picture recognition speed, spatial working memory speed and speed of memory: processes that are more aligned with the acute situation. Although we did not measure cortisol and insulin responses in children, it can be hypothesised that the effect of Iso-2.5 GUM on acute brain function is a combination

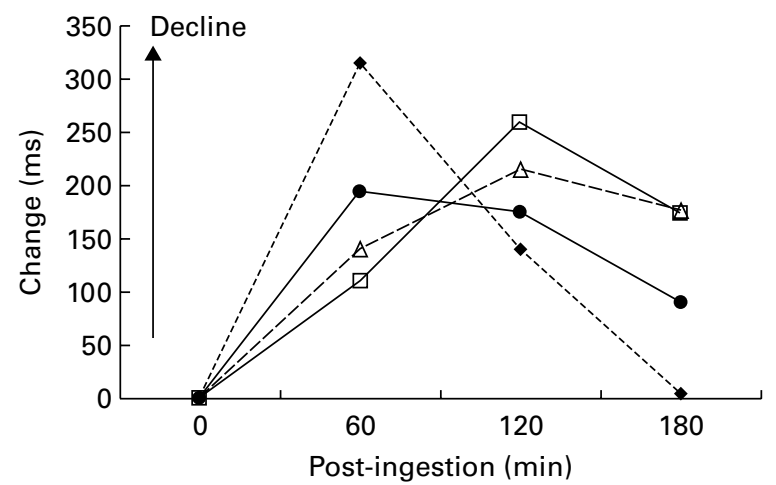

Fig. 4. Effect of the milk products on the change in choice reaction time: standard growing-up milk (Std GUM; $\square$ ); Std GUM with $5 \mathrm{~g}$ isomaltulose per serving (Iso-5 GUM; $\Delta$ ); Std GUM with $5 \mathrm{~g}$ isomaltulose per serving with lowered protein and increased fat and dietary fibre content (Iso-5 LP GUM; •); Std GUM with $2.5 \mathrm{~g}$ isomaltulose per serving and increased levels of some minerals and vitamins (Iso-2.5 GUM; $\diamond)$. Data are mean values. Iso-2.5 GUM was significantly different from Std GUM $(P<0.01)$, Iso-5 GUM $(P<0.01)$ and Iso-5 LP GUM $(P<0.02)$. For the composition of each milk product, refer to Table 2 . 


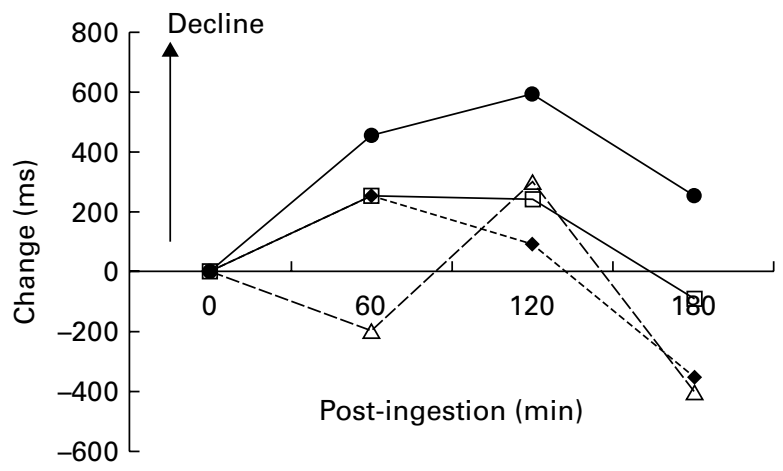

Fig. 5. Effect of the milk products on the change in speed of memory: standard growing-up milk (Std GUM; $\square$ ); Std GUM with $5 \mathrm{~g}$ isomaltulose per serving (Iso-5 GUM; $\Delta$ ); Std GUM with $5 \mathrm{~g}$ isomaltulose per serving with lowered protein and increased fat and dietary fibre content (Iso-5 LP GUM; $\bullet$ ); Std GUM with $2.5 \mathrm{~g}$ isomaltulose per serving and increased levels of some minerals and vitamins (Iso-2.5 GUM; $\bullet$ ). Data are mean values. Iso-5 GUM was significantly different from Iso-5 LP GUM $(P<0.02)$. Iso-2.5 was significantly different from Iso-5 LP GUM $(P=0.003)$. For the composition of each milk product, refer to Table 2.

of higher absolute blood glucose concentrations in the first instance ('high' GI), the insulin response and possibly associated cortisol stimulation, and a longer provision of glucose by isomaltulose. At that time, also endogenous glucose production has started due to the expected glucagon synthesis.

Both plasma insulin and glucagon secretions can be significantly stimulated by already low dietary protein intakes $(0.25 \mathrm{~g} / \mathrm{kg} \text { body weight })^{(18)}$. Since the protein levels of the GUM used in the present study ranged from 0.2 to $0.28 \mathrm{~g} / \mathrm{kg}$ body weight, a stimulation of insulin secretion, followed by a stronger decrease in blood glucose concentrations, and, finally, an associated stimulation of glucagon after 100210 min post-consumption of the GUM can be expected ${ }^{(18,26)}$. Std GUM, Iso-5 GUM and Iso-2.5 GUM supplied on average $0.28 \mathrm{~g}$ protein $/ \mathrm{kg}$ body weight. It was hypothesised that a lower protein content $(0.2 \mathrm{~g} / \mathrm{kg}$ body weight: Iso- $5 \mathrm{LP}$ GUM) could result in better cognitive performance at $3 \mathrm{~h}$ post-dose due to higher blood glucose concentrations because of a blunted insulin response when compared with the products with higher protein concentrations. Table 4 shows that Iso-5 LP GUM, in particular, stimulates parameters of attention. In contrast, Iso-5 GUM that only differed from Iso-5 LP GUM in having a higher protein content showed superior to Iso-5 LP GUM in parameters of working memory. As also suggested by Micha et al. ${ }^{(11)}$ and as discussed previously, the height of blood glucose concentration and consequently insulin and possible cortisol responses seem to be important in the activation of specific brain domains dealing with acute or more long-term activities. For Iso-5 LP GUM, it can be hypothesised that the role of cortisol is reduced due to a lower insulin response (low protein), resulting in a slower decline of blood glucose. During this decline, there is still the provision of glucose from isomaltulose (up to $3 \mathrm{~h}$ post-consumption) and a gradually increasing supply of glucose from liver glycogen breakdown (glucagon). Altogether, this might be favourable for numeric working memory (less acute and necessity for recall) as well as for the effects on attention.
The present study indicates that additional minerals ( $\mathrm{Mg}, \mathrm{Zn}$ and Se) and vitamins ( $\mathrm{D}_{3}, \mathrm{~B}_{1}, \mathrm{~B}_{2}, \mathrm{~B}_{12}$ and folic acid), and choline have a positive effect on parameters of attention and memory. An effect of micronutrient enrichment (Fe, $\mathrm{Zn}$ and the vitamins $\mathrm{A}, \mathrm{B}_{6}, \mathrm{~B}_{12}$ and $\mathrm{C}$, and folic acid) on parameters of cognitive performance (verbal learning and memory) has also been reported by the NEMO (Nutrition Enhancement for Mental Optimization) study group ${ }^{(27)}$ in well-nourished, school-aged Australian and Indonesian children, aged 6-10 years. However, the authors did not see an effect on attention. It can be debated what the impact of the additional micronutrients in Iso-2.5 GUM was on the overall good performance of the product. However, since the products with higher concentrations of isomaltulose performed less well on some specific tasks, an important role of the micronutrients is to be expected. Future studies on the 'real' benefit of a high or reduced concentration of isomaltulose in combination with the additional mix of minerals and vitamins are warranted.

Iso-2.5 GUM was the final product consumed by all children, which might have affected the outcome of the present study. This construction was chosen since due to the additional vitamins and minerals in the product Iso- 2.5 GUM, a randomised cross-over study including all products would require long washout periods. Our purpose was to study the children in a limited period of time to prevent increases in variability due to their normal improvements in cognitive performance. The total study period per child was 2 months, and although even in this period normal improvement of cognitive performance is likely to take place, the period is considered to be too short to explain the overall superiority of the product Iso-2.5 GUM. This topic will be addressed in future studies using a parallel design. A washout period between the randomised products having all the same vitamin and mineral composition was not considered to be necessary. This is confirmed by an absence in differences in cognitive outcomes after the first consumption of the products (start of the study) and consumption on day 14, in a limited number of infants per group ( $n$ 18).

\section{Conclusions}

The present study shows the beneficial effects of isomaltuloseenriched GUM on parameters of cognitive performance. Significant better effects were found for most parameters of attention, working memory and speed of memory at $3 \mathrm{~h}$ post-dose, when compared with the reference product. Furthermore, it is indicated that enrichment with specific minerals and vitamins has an additional positive effect on cognitive performance. Lowering the protein concentration resulted in improved attention but did not benefit speed of memory. The observed effects of the several products are caused by an interplay, especially, between the GI of dietary carbohydrates, the short- and long-term blood glucose concentrations, insulin and possible cortisol responses, and the protein effect on insulin and glucagon. In particular, isomaltulose and its associated longer supply of glucose seem to be of importance since this carbohydrate is the major difference with the reference product. It can be hypothesised that for 
short-term cognitive performance, a higher blood glucose concentration with associated insulin and cortisol responses seems to be beneficial. For long-term cognitive performance, low protein in combination with low GI might be preferred.

\section{Acknowledgements}

The authors are indebted to the research team from the Department of Psychiatry, Medical School, University of Indonesia for their expert analysis. FrieslandCampina Indonesia is gratefully acknowledged for supplying the products and for the regular monitoring of the study. A. S. wrote the study protocol; R. S., T. W. and D. N. were responsible for the data collection; S. B. was responsible for the study from an institutional point of view. All authors were involved in the writing of the manuscript. The results of the present study will be used by FrieslandCampina in medical marketing but FrieslandCampina had no influence on the outcome of the study. None of the other authors or the research institute had any conflicts of interest. FrieslandCampina provided the test products and the budget for the study but was not involved in the selection of participants, cognitive performance testing, the supply of products and the final set of results. Statistical analyses were conducted by W. C. from StatistiCal who was unaware of the composition of the products.

\section{References}

1. Widenhorn-Muller K, Hille K, Klenk J, et al. (2008) Influence of having breakfast on cognitive performance and mood in 13-to-20-year-old high school students: results of a crossover trial. Pediatrics 122, 279-284.

2. Benton D \& Jarvis M (2007) The role of breakfast and a midmorning snack on the ability of children to concentrate at school. Physiol Behav 90, 382-385.

3. Lopez-Sobaler AM, Ortega RM, Quintas ME, et al. (2003) Relationship between habitual breakfast and intellectual performance in well nourished school children in Madrid. Eur J Clin Nutr 57, 49-53.

4. Benton D, Ruffin MP, Lassel T, et al. (2003) The delivery rate of dietary carbohydrates affects cognitive performance in both rats and humans. Psychopharmacol 66, 86-90.

5. Wesnes KA, Pincock C, Richardson D, et al. (2003) Breakfast reduces declines in attention and memory over the morning in schoolchildren. Appetite 41, 329-331.

6. Smith AP, Clark K \& Gallagher J (1999) Breakfast cereal and caffeinated coffee: effects on working memory, attention, mood and cardiovascular function. Physiol Behav 67, 9-17.

7. Benton D \& Parker PY (1998) Breakfast, blood glucose and cognition. Am J Clin Nutr 67, 772S-778S

8. Hoyland A, Lawton CL \& Dye L (2008) Acute effects of macronutrient manipulations on cognitive test performance in healthy young adults: a systematic research review. Neurosci Biobehav Rev 32, 72-85.

9. Ingwersen J, Defeyter MA, Kennedy DO, et al. (2007) A low glycaemic index breakfast cereal preferentially prevents children's cognitive performance from declining throughout the morning. Appetite 49, 240-244.

10. Mahoney CR, Taylor HA, Kanarek RB, et al. (2005) Effect of breakfast composition on cognitive processes in elementary school children. Physiol Behav 85, 635-645.
11. Micha R, Rogers PJ \& Nelson M (2011) Glycaemic index and glycaemic load of breakfast predict cognitive function and mood in school children: a randomised controlled trial. Br J Nutr 106, 1552-1561.

12. Lina BA, Jonker D \& Kozianowski G (2002) Isomaltulose (Palatinose): a review of biological and toxicological studies. Food Chem Toxicol 40, 1375-1381.

13. Cho MH, Park SE, Lim JK, et al. (2007) Conversion of sucrose into isomaltulose by Enterobacter sp. FMB1, an isomaltuloseproducing microorganism isolated from traditional Korean food. Biotechnol Lett 29, 453-458.

14. Dye L, Gilsenan MB, Quadt F, et al. (2010) Manipulation of glycaemic response with isomaltulose in a milk-based drink does not affect cognitive performance in healthy adults. Mol Nutr Food Res 54, 506-515.

15. Holub I, Gostner A, Theis S, et al. (2010) Novel findings on the metabolic effects of the low glycaemic carbohydrate isomaltulose (Palatinose ${ }^{\mathrm{TM}}$ ). Br J Nutr 103, 1730-1737.

16. Kashimura J, Nagai $\mathrm{Y} \&$ Ebashi $\mathrm{T}$ (2003) The effect of palatinose on mental concentration in humans. J Nutr Sci Vitaminol 49, 214-216.

17. Taib MNM, Shariff ZM, Wesnes KA, et al. (2012) The effect of high lactose-isomaltulose on cognitive performance of young children. A double blind cross-over design study. Appetite 58, 81-87.

18. Claessens M, Calame W, Siemensma AD, et al. (2009) The effect of different hydrolysate/carbohydrate mixtures on postprandial glucagon and insulin responses in healthy subjects. Eur J Clin Nutr 63, 48-56.

19. World Health Organization. (WHO) (2006) WHO Child Growth Standards. Geneva: WHO Press.

20. Kleinbaum DG, Kupper LL, Muller KE, et al. (1998) Applied Regression Analysis and Other Multivariable Methods, 3rd ed. California: Duxbury Press.

21. Chen CLH, Willis BA, Mooney L, et al. (2010) Cortisol response to individualized graded insulin infusions: a reproducible biomarker for CNS compounds inhibiting HPA activation. Br J Clin Pharmacol 70, 886-894.

22. Chapotot F, Gronfier C, Jouny C, et al. (1998) Cortisol secretion is related to electroencephalographic alertness in human subjects during daytime wakefulness. J Clin Endocrinol Metab 83, 4263-4268.

23. Vgontzas AN, Pejovic S, Zoumakis E, et al. (2007) Daytime napping after a night of sleep loss decreases sleepiness, improves performance, and causes beneficial changes in cortisol and interleukin-6 secretion. Am J Physiol Endocrinol Metab 292, E253-E261.

24. Shemesh E, Rudich A, Harman-Boehm I, et al. (2012) Effect of intranasal insulin on cognitive function - a systematic review. J Clin Endocrinol Metab 97, 366-376.

25. Plum L, Belgardt BF \& Brüning JC (2006) Central insulin action in energy and glucose homeostasis. J Clin Invest 116, 1761-1766.

26. Gannon MC, Nuttall FQ, Saeed A, et al. (2003) An increase in dietary protein improves the blood glucose response in persons with type 2 diabetes. Am J Clin Nutr 78, 734-741.

27. Osendarp SJ, Baghurst KI, Bryan J, et al. (2007) Effect of a 12-mo micronutrient intervention on learning and memory in well-nourished and marginally nourished school-aged children: 2 parallel, randomized, placebo-controlled studies in Australia and Indonesia. Am J Clin Nutr 86, 1082-1093.

28. Foster-Powel K, Holt SHA \& Brand-Miller JC (2002) International table of glycaemic index and glycaemic load values: 2002. Am J Clin Nutr 76, 5-56. 